\section{Hormone Receptor Assessment of Metastatic Breast Carcino- ma by Fine Needle Aspiration Utilizing Cell Blocks and Cell Transfer Techniques: An Im- munocytochemical Review of 163 Consecutive Cases}

\section{Howard $\mathrm{H}$ Wu* and Megan Alderman}

Department of Pathology and Laboratory Medicine, Indiana University School of Medicine, Indianapolis, Indiana, USA

\begin{abstract}
Background: Fine Needle Aspiration (FNA) is an increasingly utilized diagnostic modality for diagnosing metastatic breast carcinoma. Evaluation of hormone receptor status in the setting of metastatic breast disease is standard of practice. There is limited data assessing the hormone receptor status of metastatic breast carcinoma in FNA specimens, particularly with regards to cell transfer techniques when there is inadequate tumor volume in the cell block.

Design: All FNA cases diagnosed as primary or metastatic breast carcinoma from 2010-2014 were reviewed. When performed at the time of original diagnosis, immunocytochemical stain interpretations of Estrogen Receptor (ER), Progesterone Receptor (PR), and HER2 by either cell transfer or cell block techniques were recorded. Cell transfer was performed on cases in which insufficient tumor material was present in the cell block.

Results: Hormone receptor immunocytochemical stains were attempted in 56\% (163/291) of FNA specimens diagnosed as primary (4/291) or recurrent/metastatic (287/291) breast carcinoma. Immunocytochemical interrogation was performed by cell transfer technique in $24(15 \%)$ cases and by cell block evaluation in 139 $(85 \%)$ cases. Among all cases in which immunocytochemical stains were attempted, results were issued in all but $10(6 \%)$ cases in which tumor cellularity was deemed too low ( 8 cell blocks and 2 cell transfers) for hormone status assessment. ER, PR, and HER2 were positive in $62 \%, 37 \%$, and $18 \%$ of tumor cells, respectively.
\end{abstract}

*Corresponding author: Howard $\mathrm{H} \mathrm{Wu}$, Department of Pathology and Laboratory Medicine, Indiana University School of Medicine, Indianapolis, Indiana, USA Tel: +1 3174916154; Fax: +1 3174916419; E-mail: hhwu@iupui.edu

Citation: Wu HH, Alderman M (2016) Hormone Receptor Assessment of Metastatic Breast Carcinoma by Fine Needle Aspiration Utilizing Cell Blocks and Cell Transfer Techniques: An Immunocytochemical Review of 163 Consecutive Cases. J Cytol Tissue Biol 3: 009.

Received: April 25, 2016; Accepted: June 03, 2016; Published: June 17, 2016
Conclusion: Hormone receptor status of metastatic breast carcinoma can be reliably assessed by FNA and immunocytochemistry utilizing both cell block and cell transfer techniques. Cell transfer provided $15 \%$ of the cases with biomarker results that otherwise would not have been performed due to inadequate cellularity in the cell block.

Keywords: Breast biomarkers; Cytology; Fine needle aspiration

\section{Introduction}

Fine Needle Aspiration (FNA) is a safe, minimally invasive, and relatively inexpensive diagnostic method which may be used for the evaluation of both primary and metastatic breast carcinomas. While a diagnosis can often be made primarily based on cytomorphologic features (Figure 1), adjunctive tools such as Immunocytochemistry (ICC) and Fluorescence In Situ Hybridization (FISH) are often required to assess for the presence or absence of Estrogen Receptor (ER), Progesterone Receptor (PR), and Human Epidermal Growth factor 2 (HER2) in breast carcinomas, findings of which have well established prognostic and therapeutic implications [1]. FNA can provide cellular material which may be used for determining the ER, PR, and HER2 status of both primary and metastatic breast carcinomas. The detection of these markers on FNA samples has been studied on direct smears, cytospin slides, liquid-based preparations, cell block sections and cell-transferred cytologic smears with variable success rates [2-8]. There is limited data assessing the hormone receptor status of metastatic breast carcinoma in FNA specimens, particularly with regards to cell transfer techniques when there is inadequate tumor volume in the cell block.

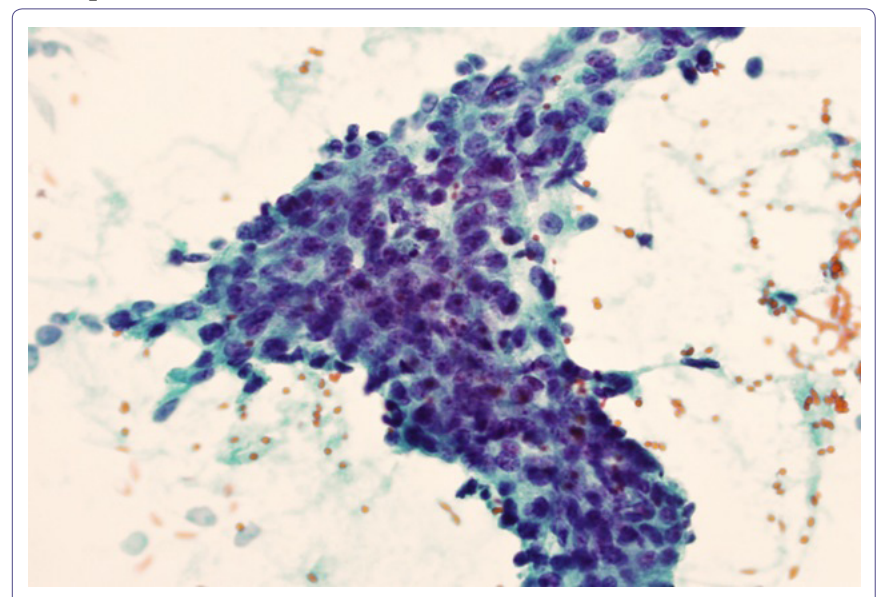

Figure 1: FNA smear of metastatic ductal carcinoma of the breast (Papanicolaou stained, x400).

\section{Materials and Methods}

This study was approved by the Institutional Review Board of the Indiana University School of Medicine. A computerized search of Indiana University Health cytopathology archives was performed. FNA cases diagnosed as primary or metastatic breast carcinoma in which ICC for ER, PR, and HER2 had been previously evaluated on either a cell block or (when there was insufficient tumor on the cell 
block) cell-transferred direct smears were identified over a five-year period (2010-2014). The cell transfer protocol previously validated by Ferguson et al., was utilized [8]. The search yielded a total of 163 FNA specimens with a diagnosis of either primary or metastatic breast carcinoma in which ICC had been attempted. ICC for ER, PR, and HER2 was performed on the cell block or when insufficient tumor volume was present on the cell block, on cell-transfer slides using commercially available antibodies. The antibody clones and detection systems used were ID-5 and LSAB for ER, 636 and LSAB- 2 for PR, and Hercep Test antibody and dextran polymer conjugated peroxidase for HER2. No modifications were made in the immunostaining process on the cell-transferred slides compared to formalin-fixed tissue. The assessment of hormone receptor status at the time of original diagnosis, which followed ASCO (American Society of Clinical Oncology) and CAP (College of American Pathologists) guidelines, was recorded.

\section{Cell Transfer Technique}

One representative ethanol-fixed Papanicolaou-stained direct smear containing adequate tumor cells was selected for ICC. The cell-transfer technique was performed as follows:

1) The coverslip was removed using histologic grade Xylene

2) A thin layer of Mount Quick ${ }^{\text {max }}$ media (Daido Sangyo Co., Ltd, Japan) was spread uniformly over the top of the cellular material

3) The slide was then placed into a $60^{\circ} \mathrm{C}$ heated oven for approximately 2-3 hours (or until hardened to the touch)

4) A Sharpie ${ }^{\text {tx }}$ marker was used on the surface of the dried media to divide the slide into multiple areas of interest

5) The slide was then placed into a Coplin jar of de-ionized water and submerged into a warm water bath at $45 \pm 3^{\circ} \mathrm{C}$ for 30 minutes to 2 hours or until the media was soft enough to easily peel away from the slide

6) The media was cut along the marked areas and each section was carefully arranged on a new positively charged glass slide (Leica InJet Plus)

7) Gentle pressure was then applied to each section using a moistened gauze pad

8) The slides were left to dry in a warm oven $\left(37-60^{\circ} \mathrm{C}\right)$ for at least 2 hours, or until the slide was completely dry to the touch

9) The dried slides were soaked in 4 exchanges of xylene (15 minutes each) in order to remove the mounting media

10) Slides were then rehydrated using 2 exchanges of absolute alcohol, 2 exchanges of $95 \%$ alcohol and 2 exchanges of de-ionized water

11) ICC staining was performed

For the cell transfer technique, the ICC procedure was identical to that used for regular immunohistochemistry for formalin-fixed paraffin embedded tissue. No destaining was applied in our process. The ICC was stained using the Dako Autostainer Link 48 with antigen retrieval.

The positive nuclear staining pattern for ER and PR on cell-transferred smears is similar to that of standard formalin-fixed paraffin embedded tissue (Figures 2 and 3). Positive (3+) HER2 expression on the cell-transferred smears typically appeared very dark and nontransparent, which was easily identified on low magnification (Figure 4). The circumferential membranous staining pattern which is characteristically seen on histologic sections was replaced by this dark, opaque staining pattern on the cell-transferred direct smears [8]. This is due to the three dimensional nature of the tumor cell clusters on the direct smears compared to the more two dimensional nature of the histologic sections. ICC results were excluded from the study if the cell transfer slide contained less than 50 cells.

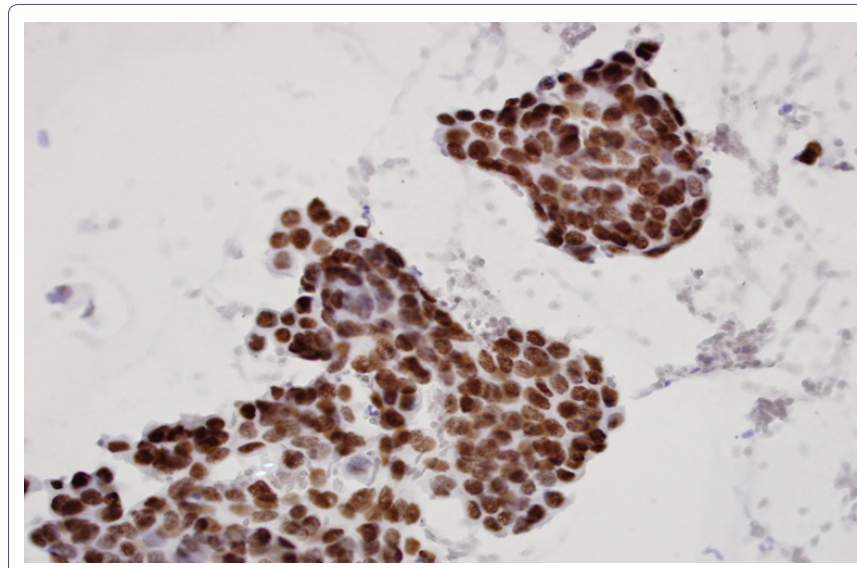

Figure 2: Estrogen Receptor (ER)-Positive, diffuse strong nuclear staining x 400 (cell-transferred smear).

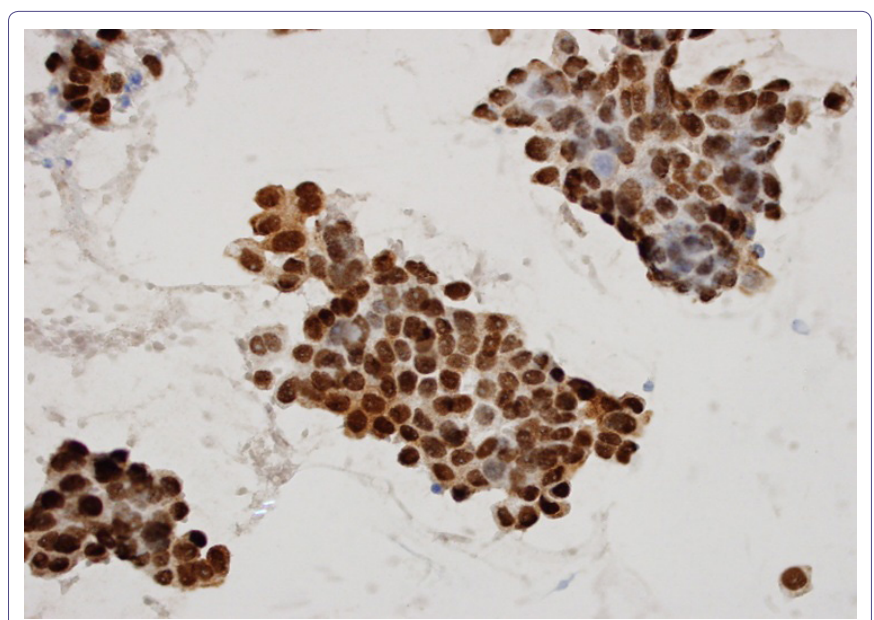

Figure 3: Progesterone receptor (ER)-Positive, diffuse strong nuclear staining, $x 400$ (cell-transferred smear).

\section{Results}

Hormone receptor immunocytochemical stains were attempted in $56 \%(163 / 291)$ of FNA specimens diagnosed as primary (4/291) or recurrent/metastatic (287/291) breast carcinoma. Immunocytochemical interrogation was performed by cell transfer technique in 24 (15\%) cases and by cell block evaluation in 139 (85\%) cases. Among all cases in which immunocytochemical stains were attempted, results were issued in all but $10(6 \%)$ cases in which tumor cellularity was deemed too low ( 8 cell blocks and 2 cell transfers) for hormone status assessment. The ICC studies for ER, PR and HER2 were successfully performed in 160/163 (98\%), 158/160 (99\%) and 148/155 (95\%) of FNA samples and ER, PR, and HER2 were positive in 99/160 (62\%), $59 / 158(37 \%)$, and 26/148 (18\%) of cases, respectively (Table 1). 


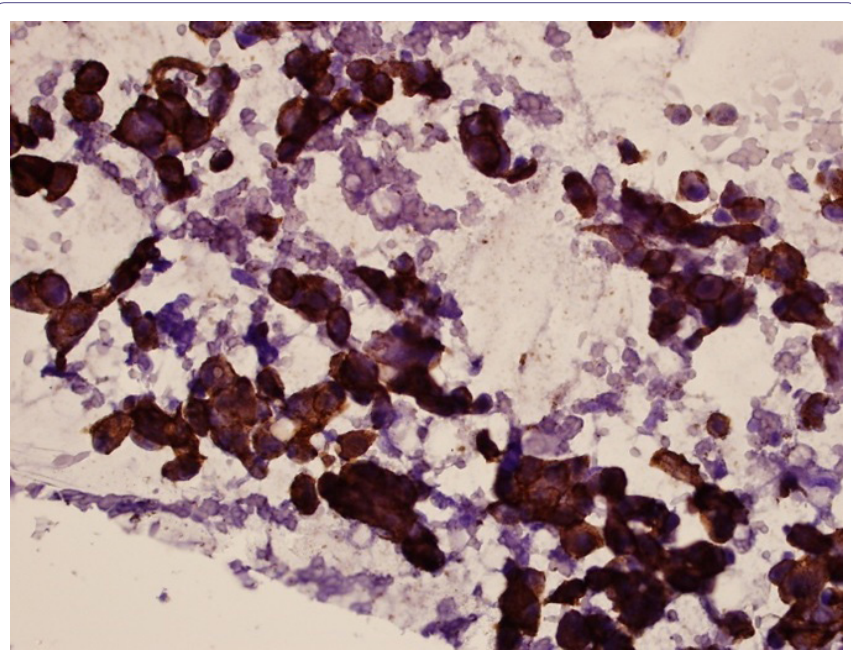

Figure 4: HER2 - Positive (3+), intense, dark staining on the tumor cells $\times 400$ (cell-transferred smear).

\begin{tabular}{|c|c|c|c|c|c|}
\hline & Positive & Negative & Equivocal & $\begin{array}{c}\text { Insufficient } \\
\text { cells }\end{array}$ & Total cases \\
\hline ER & 99 & 61 & 0 & 3 & 163 \\
\hline PR & 59 & 99 & 0 & 2 & 160 \\
\hline HER2 & 36 & 90 & 32 & 7 & 155 \\
\hline
\end{tabular}

Table 1: Results of immunocytochemistry for Estrogen Receptor (ER), Progesterone Receptor (PR) and HER2 on fine needle aspiration samples.

ER positive: $\geq 1 \%$ strong nuclear staining

PR positive: $\geq 1 \%$ strong nuclear staining.

HER2 positive (3+): Complete, intense, circumferential membrane staining in $>10 \%$ of invasive tumor cells

HER2 equivocal (2+): Incomplete and/or weak to moderate circumferential membrane staining in $>10 \%$ of invasive tumor cells or complete, intense, circumferential membrane staining in $\leq 10 \%$ of invasive tumor cells

\section{Discussion}

The status of ER, PR and HER2 in breast carcinoma is very important as a prognostic factor and is essential for the selection of appropriate treatment. It is recommended that hormone receptor and HER2 testing be performed on all primary breast carcinomas and on recurrent or metastatic tumors [9-12]. The initial diagnosis of primary breast carcinoma is typically rendered by image-guided stereotactic core biopsies. However, for metastatic/recurrent breast carcinoma, FNA is a safe and cost effective method to obtain diagnostic materials. In the setting of metastatic breast cancer, obtaining adequate tumor volume by FNA for hormone receptor assessment and HER2 status is of utmost importance. Testing for ER, PR, and HER2 by immunohistochemistry has been developed for use on formalin-fixed, paraffin-embedded tissue obtained by surgical biopsies, and the American Society of Clinical Oncology/College of American Pathologists guidelines recommend using only tissue samples fixed in $10 \%$ phosphate buffered formalin for HER2 testing [13]. Previous studies have demonstrated that Immunocytochemical staining (ICC) for ER, PR, and HER2 performed on formalin-fixed, paraffin-embedded cell blocks prepared from both FNA and serous effusion samples are reliable [3]. However, cell blocks sometimes lack adequate cellularity even when the direct smears are abundantly cellular. The cell transfer technique is a very useful method for obtaining cellular material for immunostaining and molecular testing if conventionally prepared cell blocks lack adequate cellularity [8, 14-19]. In our study $15 \%(24 / 163)$ of breast biomarker studies were performed on the cell-transferred smears that otherwise would not have been performed due to inadequate cellularity in the cell block. There are several advantages to using the cell transfer technique. It is technically simple and can be easily taught to and performed by a cytotechnologist or histotechnologist. No special equipment is required to perform the technique and the cost is relatively low. Furthermore, even if few diagnostic smears are available for a particular case, multiple immunostains can be performed from a single cellular smear. In addition to ER, PR, and HER2, we can perform GATA3 or mammaglobin ICC on a single cellular smear using the cell transfer technique to confirm the tumor origin from a breast primary. One important limitation to the use of CTT is that only ethanol-fixed direct smears can be used, as air-dried, methanol-fixed slides have previously been shown to have a false negative rate of approximately $30 \%$ and also often demonstrate nonspecific background staining [16].

Biomarker status of metastatic breast carcinoma can be reliably assessed by FNA and immunocytochemistry utilizing both cell block and cell transfer techniques. Our study demonstrates a successful rate of $94 \%$ (153/163) on providing the ICC results of ER, PR and HER2 on FNA specimens of metastatic/recurrent breast carcinoma.

\section{References}

1. Leong AS, Zhuang $Z$ (2011) The changing role of pathology in breast cancer diagnosis and treatment. Pathobiology 78: 99-114.

2. Hanley KZ, Birdsong GG, Cohen C, Siddiqui MT (2009) Immunohistochemical detection of estrogen receptor, progesterone receptor, and human epidermal growth factor receptor 2 expression in breast carcinomas: comparison on cell block, needle-core, and tissue block preparations. Cancer 117: 279-288.

3. Shabaik A, Lin G, Peterson M, Hasteh F, Tipps A, et al. (2011) Reliability of Her2/neu, estrogen receptor, and progesterone receptor testing by immunohistochemistry on cell block of FNA and serous effusions from patients with primary and metastatic breast carcinoma. Diagn Cytopathol 39: 328-332.

4. Cano G, Milanezi F, Leitão D, Ricardo S, Brito MJ, et al. (2003) Estimation of hormone receptor status in fine-needle aspirates and paraffin-embedded sections from breast cancer using the novel rabbit monoclonal antibodies SP1 and SP2. Diagn Cytopathol 29: 207-211.

5. Krishnamurthy S, Dimashkieh H, Patel S, Sneige N (2003) Immunocytochemical evaluation of estrogen receptor on archival Papanicolaou-stained fine-needle aspirate smears. Diagn Cytopathol 29: 309-314.

6. Beatty BG, Bryant R, Wang W, Ashikaga T, Gibson PC, et al. (2004) HER-2/ neu detection in fine-needle aspirates of breast cancer: fluorescence in situ hybridization and immunocytochemical analysis. Am J Clin Pathol 122: 246255.

7. Kumar SK, Gupta N, Rajwanshi A, Joshi K, Singh G (2012) Immunochemistry for oestrogen receptor, progesterone receptor and HER2 on cell blocks in primary breast carcinoma. Cytopathology 23: 181-186.

8. Ferguson J, Chamberlain P, Cramer HM, Wu HH (2013) ER, PR, and Her2 immunocytochemistry on cell-transferred cytologic smears of primary and metastatic breast carcinomas: a comparison study with formalin-fixed cell blocks and surgical biopsies. Diagn Cytopathol 41: 575-581.

9. National Comprehensive Cancer Network (NCCN) (2013) Clinical Practice Guideline in Oncology (NCCN Guidelines $\left.{ }^{\circledR}\right)$ Version 3. National Comprehensive Cancer Network (NCCN), Washington, PA, USA.

10. Harris L, Fritsche H, Mennel R, Norton L, Ravdin P, et al. (2007) American Society of Clinical Oncology 2007 update of recommendations for the use of tumor markers in breast cancer. J Clin Oncol 25: 5287-5312.

11. Pusztai L, Viale G, Kelly CM, Hudis CA (2010) Estrogen and HER-2 receptor discordance between primary breast cancer and metastasis. Oncologist 15: 1164-1168. 
Citation: Wu HH, Alderman M (2016) Hormone Receptor Assessment of Metastatic Breast Carcinoma by Fine Needle Aspiration Utilizing Cell Blocks and Cell Transfer Techniques: An Immunocytochemical Review of 163 Consecutive Cases. J Cytol Tissue Biol 3: 009.

12. Arslan C, Sari E, Aksoy S, Altundag K (2011) Variation in hormone receptor and HER-2 status between primary and metastatic breast cancer: review of the literature. Expert Opin Ther Targets15: 21-30.

13. Hicks DG, Schiffhauer $L$ (2011) Standardized assessment of the HER2 status in breast cancer by immunohistochemistry. Lab Medicine 42: 459-467.

14. Wu HH, Jones KJ, Cramer HM (2013) Immunocytochemistry performed on the cell-transferred direct smears of the fine-needle aspirates: a comparison study with the corresponding formalin-fixed paraffin-embedded tissue. Am J Clin Pathol 139: 754-758.

15. Wu HH, Eaton JP, Jones KJ, Cramer HM, Randolph ML, et al. (2014) Utilization of cell-transferred cytologic smears in detection of EGFR and KRAS mutation on adenocarcinoma of lung. Mod Pathol 27: 930-935.
16. Marshall AE, Cramer HM, Wu HH (2014) The usefulness of the cell transfer technique for immunocytochemistry of fine-needle aspirates. Cancer Cytopathol 122: 898-902.

17. Chen S, Randolph M, Cramer HM, Watkins T, McCullough H, et al. (2014) Detection of BRAF mutation in metastatic melanoma utilizing cell-transferred cytological smears. Acta Cytol 58: 478-482.

18. Shi Q, Ibrahim A, Herbert K, Carvin M, Randolph M, et al. (2015) Detection of BRAF mutations on direct smears of thyroid fine-needle aspirates through cell transfer technique. Am J Clin Pathol 143: 500-504.

19. Zhang C, Randolph ML, Jones KJ, Cramer HM, Cheng L, et al. (2015) Anaplastic Lymphoma Kinase Immunocytochemistry on Cell-Transferred Cytologic Smears of Lung Adenocarcinoma. Acta Cytol 59: 213-218. 